\title{
Using GIS to Analysis Runoff Change in Land Utilization of Foping, Nature Reserve, Shanxi Province
}

\author{
Yi GUO, Xiaoping HUANG, Jingqian PENG \\ China University of Geosciences, College of Jiangcheng, Wuhan 430020
}

\begin{abstract}
Land use is an indicator of the interaction between human and the environment on the earth surface. Recently, an increasing attention has been paid to the issue of impact of land use and land cover change on environment and water quality. In this paper, we analyzed the land use and land cover change by using RS and GIS, and simulated its implications in runoff from 1991 to 2000 using SCS model in the Foping Nature Reserve, Shan 'xi Province. Our results showed that this region were main plantation, woodland and grassland. Woodland area increased significantly, while plantation and grassland area decreased, which would greatly affect runoff. Meanwhile, the results show that woodland area and land cover area are negatively correlated with the runoff.
\end{abstract}

Keywords: SCS model; runoff; land use and land cover

\section{陝西佛坪土地利用GIS分析徑流變化}

\author{
郭 昳, 黃曉萍, 彭晶倩 \\ ${ }^{1}$ 中國地質大學江城學院 430020
}

\begin{abstract}
摘 要: 土地利用是人與環境互動展現在地表的現象, 全球土地利用的變化對環境无其是對水環境的影響已得到 廣泛的關注。本研究以位於秦嶺的陝西佛坪地區為例,在利用 GIS/RS 手段對其土地利用/土地覆蓋變化分析的基礎 上, 結合 SCS 模型類比該地區 1991-2000 年 10 年間的徑流量的變化與土地利用之間的關係。結果表明: 該地區 土地利用類型主要以耕地、林地和草地為主, 其中林地面積在十年裏顯著增長, 耕地和草地面積不斷減少。土地 利用變化對徑流有較顯著的影響，林地面積和植被覆蓋面積的增加導致了徑流量減少。其結果對於我國山地的植 被恢復與水資源保護具有一定的指導意義.
\end{abstract}

關鍵字：SCS 模型；徑流量；土地利用

\section{1. 引言}

中國是一個水資源短缺的國家，人均水資源佔有 量只有兩千兩百立方米。同時, 受季風氣候和地形條 件的綜合影響, 中國水資源時空分佈極不均衡。近二 十年來，隨著人口增加、國民經濟持續快速發展、城 市化進程的加快和人民生活水準的不斷提高以及自然 環境的變化, 我國的洪淡災害、乾旱缺水、水土流失 和水污染等問題日趨嚴重。水資源短缺、過度地圍湖
造地，侵佔河道、水體污染等，這些都造成了嚴重的 生態問題, 並成為制約我國經濟社會可持續發展的重 要因素。

在水資源嚴重不足的同時，我國每年還有大量的 可用水被污染。一般來講, 水體污染主要分為點源污 染和非點源污染，點源污染可以通過工程的手段得到 較好的控制, 而非點源污染對環境的影響則難以測量 與評估。其中土地利用的改變是非點源污染形成的重 要因素之一。 
土地利用與植被變化對流域水文環境、水文過 程、水量平衡、水文化學以及流域生態系統都會產生 十分重要的影響 $[1,2]$ 。土地利用與植被變化, 一方面 影響流域的蒸發性能, 另一方面通過地表覆蓋類型及 程度的改變影響地表徑流的產生, 土壤的入滲特徵, 進而影響流域地下水形成, 從而使流域產匯流量與過 程發生改變。因此, 土地利用變化, 如造林或毀林、 森林火災、城市化等對水文動態變化的影響已成為全 球變化研究的熱點。

SCS模型是美國農業部水土保持局研發的水文模 型, 主要用於小流域工程規劃中水土保持及防洪設 計、城市水文及無資料流域。目前該模型在美國及一 些其他國家得到了廣泛的應用, 並取得了較好效果 $[1$, 3]。隨著我國社會經濟的迅速發展, 土地利用方式和 強度對流域產流的影響已成為當前水文科學領域研究 的熱點, 土地利用變化對流域徑流變化及產匯流機制 的影響成為目前亟待解決的問題, 因此, SCS模型在 我國水資源保護中具有廣泛的應用前景 $[4]$ 。

一般而言, 研究土地利用變化對流域徑流的影 響, 需獲取土地利用等流域下熱面資料以及水文、氣 象資料, 而對於水文、氣象資料較缺乏的流域, 使用 一般的水文模型(如徑流係數法、等時線法)很難對流 域徑流過程進行模擬。更重要的是土地利用資料、地 形資料是地理資訊資料處理得到的結果，這種面狀的 遙感資訊與傳統的水文模型的參數和結構不相適應 [5],同時傳統的水文模型很少直接或間接將土地利用 狀況、土壤濕度特徵等作為影響因素在模型應用中加 以考慮。因此, 建立基於地理資訊或遙感水文模型進 行流域徑流過程類比, 以提高精度成為一種必然的要 求。本文以美國農業部水土保持局研發的SCS模型為 基礎, 結合地理資訊方法對陝西佛坪地區降雨-徑流過 程進行模擬, 為揭示土地利用變化條件下流域的降雨徑流關係及洪水災害預報提供理論依據和科學方法。

\section{SCS模型的基本原理}

\subsection{SCS模型的基本原理}

$\mathrm{SCS}$ 徑流模型能反映不同土壤類型、不同地利用 方式及前期土壤含水量對降雨徑流的影響, 具有簡單 易行、所需參數較少, 對觀測資料的要求很嚴格的特 點, 是一種較好的小型集水區徑流計算法。它是基於 集水區的實際入滲量 $(\mathrm{F})$ 與徑流深 $(\mathrm{Q})$ 之比等於集水區 該場降雨前的最大可能入量(或最大滯留量 $\mathrm{S}$ )與最大 可能徑流量(或潛在徑量 $\mathrm{Q}_{\mathrm{m}}$ )之比的假定基礎上建立 的, 即:

$$
\frac{F}{Q}=\frac{S}{Q_{m}}
$$

式中: 假定潛在徑流量 $\mathrm{Q}_{\mathrm{m}}$ 為降雨量 $(\mathrm{P})$ 與初始的損 耗包括表層土的儲存、截流及徑流產前的入滲 $\mathrm{I}_{\mathrm{a}}$ 的差 值，即:

$$
Q_{m}=P-I_{a}
$$

實際入滲量為降雨量減去初損和徑流量, 即:

$$
F=P-I_{a}-Q
$$

由(1),(2),(3)式可得出:

$$
Q=\frac{\left(P-I_{a}\right)^{2}}{S+P-I_{a}}
$$

式中 $\mathrm{S}$ : 最大滯留量 $(\mathrm{mm})$, 和土壤、土地利用、 坡度、土壤含水量等有關。

$$
\mathrm{S}=25.4\left[\frac{1000}{C N}-10\right]
$$

$\mathrm{CN}$ : 該天的曲線係數。Ia 通常約等於 $0.2 \mathrm{~S}$ 。方程 (4)可以寫為:

$$
Q=\frac{(P-0.2 S)^{2}}{S+0.8 S}
$$

當 $\mathrm{P}>0.2 \mathrm{~S}$ 時, 有地表徑流產生。 $\mathrm{CN}$ 值越大, $\mathrm{S}$ 值 越小，越易產生徑流; 反之, 則相反。

\section{$2.2 \mathrm{CN}$ (曲線係數)值的影響因素及確定方法}

\subsection{1 土壤類型}

在理論上, $\mathrm{CN}$ 取值介於 0-100 之間, 但在實際條 件下, CN 值在 30-100 之間變化。根據土壤特性不同, 可將土壤劃分為 A,B,C,D 四大類型, 並由此確定其 CN 值。A 類為滲透性很強, 潛在徑流量很低的一類土壤, 主要是一些具有良好透水性能的砂土或啋石土, 土壤 在水分完全飽和的情況下仍然具有很高入滲速率和導 水率。 $\mathrm{B}$ 類為滲透性較強的土壤, 主要是一些砂壤土, 或者在土壤剖面的一定深度具有一層弱不透水層, 當 土壤在水分完全飽和的情況下仍然具有較高的入滲速 率。C 類為中等透水性土壤, 主要為壤土, 或者雖為 砂性土但在土壤剖面的一定部位存在一層不透水層, 土壤在水分完全飽和的情況下保持中等入滲速率。 $\mathrm{D}$ 類為弱透水性土壤，主要為粘土等。下表 1 為雨前土 壤在中等濕潤狀態下的不同土壤類型和土地利用方式 下的 $\mathrm{CN}[6]$ 。 

表 1. 不同土壤類型和土地利用方式在 AMC I (中等濕潤程 度)條件下的 CN 值

\begin{tabular}{lcccc}
\hline & \multicolumn{4}{c}{ 不同水文土壤組 } \\
\hline 耕地 & $\mathrm{A}$ & $\mathrm{B}$ & $\mathrm{C}$ & $\mathrm{D}$ \\
林地 & 62 & 71 & 78 & 81 \\
草地 & 25 & 55 & 70 & 77 \\
城鄉、居民用地 & 72 & 58 & 71 & 78 \\
水體 & 70 & 79 & 85 & 88 \\
未利用地 & 100 & 100 & 100 & 100 \\
\hline
\end{tabular}

\subsection{2 土壤水分情況}

在利用 SCS 模型計算徑流量時, 前期土壤乾旱與 濕潤對集水區的產流所作的貢獻是不同的，所以要考 慮前期降水對徑流的影響。考慮所研究流域土壤前期 濕度條件, 並參照 $\mathrm{AMC}$ 三級劃分指標[7]來客觀定義 土壤前期濕度(見表 2)。

\section{3. 應用實例}

\section{1 佛坪地區狀況}

佛坪自然保護區位于秦嶺中段南坡, 地處陝西 南部的佛坪縣境內, 保護區管理局坐落在佛坪縣城 南, 南距漢中市 158 公里, 北離西安市 210 公里。 地處秦嶺中段南坡, 東徑 $107^{\circ} 40^{\prime}-107^{\circ} 55^{\prime}$ 、北緯 $33^{\circ} 33^{\prime}-33^{\circ} 46^{\prime}$ 。周圍與陝西省龍草坪林業局、陝西周 至國家級自然保護區、陝西老縣城自然保護區、陝 西省太白林業局、陝西長青國家級自然保護區和佛 坪縣嶽壩鄉為鄰, 東、西、北三面均以山脊為界, 南側以山脊、河流或道路劃分。東西縱深 $24.8 \mathrm{~km}$, 南北橫延 $22.0 \mathrm{~km}$, 規劃面積 $35000 \mathrm{ha}$, 實有面積 29240ha

\section{2 模型輸入資料}

\subsection{1 土地利用資料}

採用 1994 年、2000 年衛星遙感 TM 資料, 在 ERDASIMAGE 和 SWAT 模型支援下, 以 $1: 100000$ 地形圖為依據, 對上述 2 期遙感資料進行圖像處理。

表 2.SCS 模型土壤前期濕度等級劃分

\begin{tabular}{ccc}
\hline \multirow{2}{*}{$\mathrm{AMC}$} & \multicolumn{2}{c}{ 前 $5 \mathrm{~d}$ 降雨量 $/ \mathrm{mm}$} \\
\cline { 2 - 3 } 濕潤程度 & 生長期 & 休止期 \\
\hline I & $<13$ & $>28$ \\
II & $13-28$ & $36-53$ \\
III & $>28$ & $>53$ \\
\hline
\end{tabular}

利用全國土地利用現狀分類系統 $[8,9]$, 並根據陝西佛 坪地區的土地利用特點, 將研究區土地利用類型劃分 為 6 個類型: 耕地、林地、草地、耕地、水域、城鎮(鄉)、 未用地(見表 3)[2]。

\subsection{2 土壤數據}

SCS 模型將不同的土壤按照其下滲特徵分為 4 類, 本文以佛坪自然保護區統計的土壤分類圖為基礎, 對原有土壤分類進行了對應歸併, 得到了符合模型的 土壤分類結果, 並將土壤的物理特性資料按照類型輸 入到一個資料庫檔中。主要的土壤類型有黃棕壤、棕 壤、暗棕壤。

\section{3 研究方法}

研究土地利用變化的水文回應需要土地利用變 化與水文科學兩個領域的綜合研究。地理資訊系統及 $3 \mathrm{~S}$ 技術的發展，使流域地形、土壤、植被、土地利用 等下熱面地面資訊資料的數量和品質得到了大大的提 高[8]。利用 ERDAS、ENVI 對研究區 90 年代和 2000 年代兩個時期的 TM 圖像進行了土地利用/覆蓋圖像解 譯等分析處理, 並利用 ArcView 的空間分析功能和數

表 3. 中國科學院資源環境資料庫中的全國 1：10 萬土地利 用分類系統

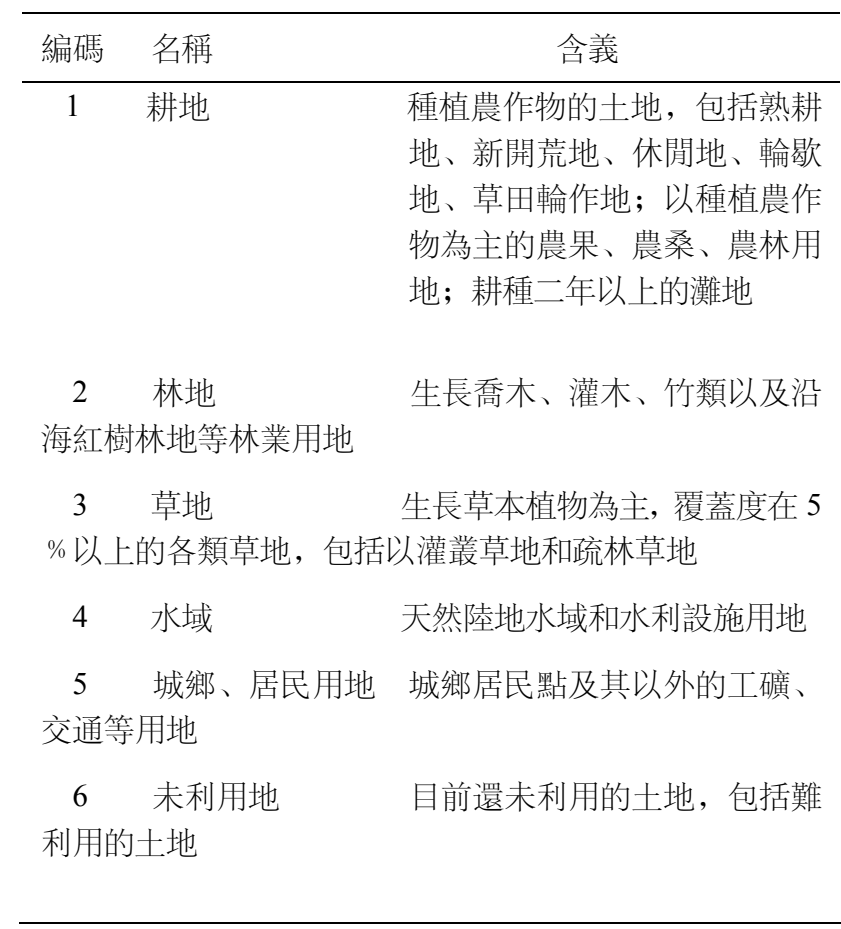


理統計方法, 借助 SCS 模型, 在流域 DEM 上進行了 流域河網生成和子流域劃分, 計算了子流域參數; 對 土壤類型和土地利用進行了重分類, 構建了資料庫, 分析不同土地利用類型對徑流量的影響機制[10]。

根據 SCS 原理, 模型中各子單元的產流計算只有 一個參數 $\mathrm{CN}$, 它是各子單元前期土壤濕潤程度 $(\mathrm{AMC})$ 、土壤類型和土地利用的函數。 $\mathrm{CN}$ 值的大小 間接地反映了流域各子單元的產流能力。一般情況 下, 當降雨一定時, 產流量較大的土地利用類型、土 壤類型、前期土壤濕潤程度, 其 $\mathrm{CN}$ 值也較大, 反之 亦然。由於 $\mathrm{CN}$ 值受降雨前流域內土壤濕潤程度的影 響, SCS 模型將土壤濕潤程度根據前 5 天的降雨總量 劃分為 3 類, 分別代表幹(AMC I )、平均(AMC II )、 濕(AMCIII)三種狀態(表 2), 不同濕潤狀況的 $\mathrm{CN}$ 值有 相互轉換關係, 然後根據 SCS 模型提供的乾旱半乾旱 地區 $\mathrm{CN}$ 值（表 1), 結合佛坪地區自條件, 確定出 流域在 AMCIII和土地利用條件下的 CN 值(表 4)。

\section{4. 結果與討論}

研究區土地利用類型主要以耕地、林地和草地為 主, 其結構 7 年來隨外界條件發生了變化(表 5)。土地 利用/土地覆被動態變化特徵為:

表 4. 不同土壤類型和土地利用方式在 $\mathrm{AMCIII}$ 條件下的 CN值

\begin{tabular}{lcccc}
\hline & \multicolumn{4}{c}{ 不同水文土壤組 } \\
\hline & $\mathrm{A}$ & $\mathrm{B}$ & $\mathrm{C}$ & $\mathrm{D}$ \\
耕地 & 79 & 85 & 89 & 91 \\
林地 & 43 & 74 & 89 & 89 \\
草地 & 69 & 84 & 92 & 92 \\
城鄉、居民用地 & 75 & 86 & 91 & 93 \\
水體 & 100 & 100 & 100 & 100 \\
未利用地 & 88 & 93 & 97 & 97 \\
\hline
\end{tabular}

表 5.1994 年和 2000 年研究區土地利用面積匯總表

\begin{tabular}{cccc}
\hline 土地利用類型 & $1994\left(\mathrm{~km}^{2}\right)$ & $2000\left(\mathrm{~km}^{2}\right)$ & 面積變化 $\left(\mathrm{km}^{2}\right)$ \\
\hline 耕地 & 4436 & 4130 & -306 \\
林地 & 26081 & 26547 & 466 \\
草地 & 569 & 379 & -190 \\
水域 & 31 & 11 & -20 \\
城鄉居民用地 & 10 & 19 & 9 \\
未利用地 & 10 & 70 & 60 \\
\hline
\end{tabular}

1)耕地、草地面積不斷減少

耕地面積由 1994 年的 $4436 \mathrm{~km}^{2}$ 減少到 2000 年的 $4130 \mathrm{~km}^{2}$, 減少 $306 \mathrm{~km}^{2}$ 。其變化主要是由於人口增加, 城市化建設步伐加快, 建設用地佔用大量耕地而致, 加之佛坪地區綠化工程政策的實施, 耕地面積呈現較 大幅度減少趨勢; 草地面積由 1994 年的 $569 \mathrm{~km}^{2}$ 減少 到 2000 年的 $379 \mathrm{~km}^{2}$ ，減少了 $190 \mathrm{~km}^{2}$ 。

2)林地、建設用地面積呈大幅度增長趨勢

林地面積由 1994 年的 $26081 \mathrm{~km}^{2}$ 增加到 2000 年的 $26547 \mathrm{~km}^{2}$ 。這是近年來, 國家和地方政府根據區域自 然條件，積極退耕還林，對佛坪生態環境進行科學規 劃與建設的成果。1994 2000 年, 建設用地面積增加 了 $9 \mathrm{~km}^{2}, 2000$ 年建設用地面積達到 $19 \mathrm{~km}^{2}$ 。其主要原 因是由於人口的增長, 城市化進程加速, 城市建設步 伐加快, 從而導致居住用地增加。而林地增加是因為 國家實施“天然林保護工程”的作用的效果。

分析結果表明，土地利用變化對年徑流有較顯著 影響。1995-2000 年植被條件較好的土地利用比 1991-1994 期間的產流有所下降，在同一降水條件下， 植被較好的土地利用比植被較差的土地利用產流減 少, 且隨著降雨的增多, 土地利用與植被變化對徑流 的影響效應增強, 這主要受土壤入滲特性及林冠截留 影響。見圖 2。

在利用 SCS 模型估算流域徑流量時, 由於我國缺 乏 $\mathrm{CN}$ 的相關資料庫, 對於 $\mathrm{CN}$ 值的選取存在一定困 難, 此外, 現有氣象監測站的數目有限, 研究獲得的 降雨資料是單個監測站測得的降雨量, 當研究區域與 監測站相距較遠時, 因降雨的分佈不均將導致輸入的 降雨資料與研究區域實際情沉有所差異, 這也將導致 模型的徑流輸出與實測值之間存在差異。

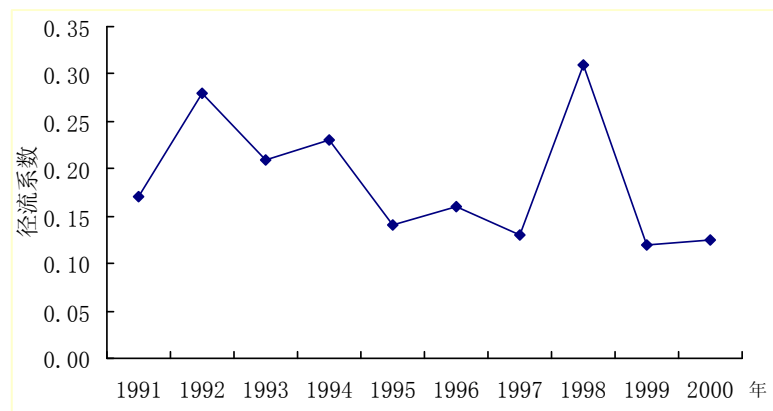

圖 1. 徑流係數變化曲線 
研究基於不同土地利用時期的資料資料進行分 析, 從氣候因素來考虑, 地表徑流不僅受降水的影響, 同時還受蒸發散等因素的影響。本文在探討不同時期 土地利用變化對水文響的影響應時，結合佛坪地區的 降雨特性，考慮氣候因素對植被變化水文回應的影響 時, 降水仍是主要因素而蒸發在其中扮演的角色則相 對較輕[11]。因此, 認為上述研究中徑流的減少仍主 要源于土地利用與植被變化。

水文迴圈及土地利用變化都具有極為複雜的空 間特性, 在 ArcView 環境下運用 SCS 模型, 目的是為 了獲得徑流估計量, 確定某一特定流域徑流計算參 數。本文僅僅分析了土地利用變化對地表徑流量的影 響, 但地形及土壤對徑流的影響, 甚至徑流對非點源 污染的權重還需要應用分散式水文模型對整個研究區 域內完整的水文過程進行更為深入的的研究。

\section{參考文獻 (References)}

[1] D. B. Booth, J. R. Karr, S. Schauman, et al. Reviving urban streams: Land use, hydrology, biology, and human behavior [J]. Journal of the American Water Resources Association, 2004, 40(5): 1351-1364.

[2] 沈澤吴, 張全發, 嶽超, 等. 南水北調中線水源區土地 利用/土地覆被的空間格局 [J]. 地理學報, 2006, 61(6): 633-644.
[3] J. R. William and W. V. Lasear. Water yield model using SCS curve numbers [J]. Journal of Hydraulics Division, 1976, 102(9): 1221-1253.

[4] 晉華, 孫西歡, 李仰斌. SCS 模型在嵐河流域的應用研 究 [J]. 太原理工大學學報, 2003, 6,735-7521.

[5] 陸家駒. 遙感資料在水文模型中的有效應用 [J]. 水文, 1990, 6, 9-14.

[6] 趙松嶺. 集水農業引論 [M]. 西安：陝西科學出版社, 1996.

[7] 張美華, 王曉燕, 秦福來. SCS 模型在密雲石匣試驗社 區降雨徑流量估算中的應用 [J]. 首都師範大學學報 (自然科學版), 2004, 25, 155-158.

[8] E. Kalnay, M. Cai. Impact of urbanization and land-use change on climate. Nature. 2003, 423, 528-531.

[9] 許彥. 基於 ArcView 的 SCS 模型在流域徑流計算中的 應用 [J]. 水土保持研究, 2006, 13(4): 176-182.

[10] 王根緒, 張鈺, 劉桂民, 等. 馬營河流域 1967 2000 年土地利用變化對河流徑流的影響 [J]. 中國科學 D 輯, 地球科學, 2005, 35(7): 671-681.

[11] 王盛萍, 張志強. 黃土高原流域土地利用變化水文動 態回應 [J]. 北京林業大學學報, 2006, 28(1): 48-54.

[12] M. Bosznay. Generalization of SCS curve numebe method [J]. Journal of Irrigation and Drainage Engineering, 1989, 155(1): 139-144.

[13] 葉寶瑩, 張養貞. 嫩江流域土地覆蓋變化對徑流量的 影響分析 [J]. 水土保持通報, 2003, 23(4): 15-18. 